\title{
Analyzing Rural Poverty Considering Multidimensional Poverty Index: A Case Study in Jalma Union
}

\author{
Pintu Kumar Sheel ${ }^{1,}$, , Titun Mukherjee ${ }^{1}$, Atikur Rahman ${ }^{2}$ \\ ${ }^{1}$ Department of Urban and Rural Planning, Khulna University, Khulna, Bangladesh \\ ${ }^{2}$ Department of Urban and Regional Planning, Pabna University of Science and Technology, Pabna, Bangladesh \\ Email address: \\ pintu4academic@gmail.com (P. K. Sheel), titun01934@gmail.com (T. Mukherjee), atikurp121714@gmail.com (A. Rahman) \\ ${ }^{*}$ Corresponding author
}

\section{To cite this article:}

Pintu Kumar Sheel, Titun Mukherjee, Atikur Rahman. Analyzing Rural Poverty Considering Multidimensional Poverty Index: A Case Study in Jalma Union. History Research. Vol. 5, No. 4, 2017, pp. 25-31. doi: 10.11648/j.history.20170504.11

Received: December 20, 2017; Accepted: January 2, 2018; Published: January 18, 2018

\begin{abstract}
The World has run on the way of prosperity in recent decades. Though it is great news for everyone, it has run up against many obstacles. Only a few number of people have grab this opportunity over the world. Most of the people are staying behind the scene. Poverty is one of the major concerns in the world. No country can overcome the curse of poverty. Within these Bangladesh is one of them, as a developing country in South Asia. The main obstacle to economic development is poverty. It is such an economic condition when one achieving a minimum living standard and losing the ability to purchase the essential living products as a result of very little income. Natural disasters such as cultural arbitrariness and aggression, population pressure, economic hardship, social and political problems, and foods, tidal waves, drought etc. create poverty. Over the world, it has measured by using some criteria and methods. Multidimensional Poverty index is one of them to measure the dimension of poverty. This paper provides new insights for the understanding, measurement, and analysis of multidimensional poverty in Jalma union, Khulna, Bangladesh. This paper makes an assessment of poverty scale in Jalma union using a comparative static approach.
\end{abstract}

Keywords: Poverty, Multidimensional Poverty Index, Poverty Identification Indicator

\section{Introduction}

\subsection{Background of Study}

Poverty has been increasing since the creation earth. Now-a-days, it has faced a demonstrate situation. Over the world it has measured based on different indicator. In this manner, the MPI (Multidimensional Poverty Index) considers the joint dispersion of deprivations; it tracks a similar individual over various measurements and checks the quantity of deprivations at the same time experienced by a person. Poverty is pronounced deprivation in well-being, and comprises many dimensions [11]. It incorporates low livelihoods and the powerlessness to procure the essential goods and services vital for survival with pride. It is articulated hardship or deprivation in prosperity, and includes many measurements (Martin, 2011). The weak correlation between economic growth and poverty are existing in this union. Poverty also encompasses low levels of health and education, poor access to clean water and sanitation, inadequate physical security, lack of voice, and insufficient capacity and opportunity to better one's life. In Jalma union, access to economic opportunities outside agriculture would help to increase consumption, but low educational attainment, poor access to financial markets, and weak infrastructure prevent many smallholders from participating in nonfarm activities. The main aim of this research is to analyze rural poverty through qualitative and quantitative ways. For this reason, the MPI considers the joint dissemination of poverty that tracks a similar individual over various measurements and tallies the quantity of hardships all the while experienced by a person. It incorporates low earnings and the failure to obtain the fundamental products and ventures vital for survival with nobility. The MPI evaluates the nature and force of destitution at the individual level, with needy individuals being the individuals who are multiply deprived and the degree of their poverty is measured by the degree of their deprivation [2]. The MPI can join a scope of markers to catch the unpredictability 
of neediness and better advice strategies to alleviate it.

\subsection{Research Objective}

The aim of this research is to find out exiting situation of poverty in Jalma union and to explore and analyze the existing status of poverty considering Multidimensional poverty index.

\section{Literature Review}

According to [14], "Poverty is articulated deprivation in well-being." This obviously makes one wonder of what is implied by well-being. One approach is think that well-being as the command over commodities in general, so people are better off if they have a greater command over resources. In this view, the principle concentrate is on whether families or people have enough resources to address their needs. Second approach is thinking that well-being is to ask whether people are able to obtain specific type of consumption good: do they have enough food, shelter, education, etc.? For this, the investigator would need to go past the more conventional fiscal measures of poverty: nutritional poverty may be measured by looking at whether children are squandered; and educational poverty might be measured by asking whether someone is ignorant, or by the measure of formal schooling they have gotten.

[10] Represents three aspects of rural poverty in Bangladesh have been examined in this paper: (a) trend of poverty over the decade of the $2000 \mathrm{~s}$, (b) evolving pattern of poverty among different population groups over the same decade, and (c) identification of the major determinants of poverty in rural Bangladesh. For the first two exercises, data from the Household Income and Expenditure Survey (HIES) 2000 of the Bangladesh Bureau of Statistics were compared with data from a large-scale survey of rural poverty carried out in 2010 by the Institute of Microfinance in Dhaka. The third exercise was based solely on the 2010 survey.

[13] Estimates capability deprivation by utilizing approaches (relative and supreme) factor analysis. He utilizes data on instructive accomplishment and degree, wellbeing condition, and word related renown as ability markers from the general social overview. He finds that the extent of capability deprivation contrasted relying upon the strategy utilized, yet in all cases, it was lower than that of income poverty.

[1] Describe the AF technique by utilizing data in Indonesia and the U.S. They utilize information from the 2004 National Health Interview Survey directed by the U.S. National Center for Health Statistics on four markers, in particular, pay measured in poverty line increases, self-revealed wellbeing, medical coverage, and years of tutoring. Be that as it may, their assessments exclusively effectively provide an observation utilization of their strategy.

\subsection{Official Poverty Measure}

[8] Focused in his paper poverty thresholds by calculating the cost of food budgets. He identifies that the poverty threshold was taken to be three times the family food budget.
For a family to be 'poor', yearly cash income (profit, benefits, premium, lease, resources and money welfare) must be not as much as the poverty threshold. The limits shift by family size and creation, and are refreshed for swelling utilizing the Consumer Price Index (CPI).

[7] Test the possibility of measuring the MPI by utilizing the Current Population Survey (CPS) and the ACS information independently. They describe and think about populace bunches by the quantity of deprivation experienced in income and other indicators. They pick five indicators to determine multidimensional poverty.

\subsection{Alternative Poverty Measures}

According to the article of [6], experiment among 836 low-income women, those receiving Aid to Families With Dependent Children (AFDC) or food stamps had experienced more coercive sexual assault, abuse by past partners, psychological abuse by current partners, and types of victimization than women not receiving assistance. The two groups of women were equally likely to endure threats or violence from current partners. African Americans and European Americans were more likely to have been victimized than Mexican Americans. European Americans reported more severe victimization except current partner violence. Multiple regressions on employment and assistance showed victimization predictors that varied by ethnicity. The effects of abuse by current partners were limited and are likely to be indirect.

[4] Focuses in the United States regarding the definition of economic poverty, measure poverty almost exclusively in terms of current income. However, there are many reasons to supplement measures of income-poverty with measures of material hardship. First, material hardship and income-poverty represent alternative conceptions of poverty. Second, material hardship is of both normative and instrumental concern. Third, hardship measures are useful tools for policy analysis, particularly in the context of welfare reform. Specific recommendations for developing and using hardship measures are presented.

[5] Their current study used the Survey of Income and Program Participation (SIPP), a large-scale U.S. survey with a large number of questions on the material circumstances of households to create a measurement model of hardship that takes this relationship into account. A higher-order model with five-first-order factors: consumer durables, resources available to meet needs, housing conditions, neighborhood problems and crime, and community services, and a single second-order factor hardship fit the data well, with the "Housing" and "Neighborhood" first-order factors most strongly related to the higher-order hardship construct. Despite our attempts to tie the hardship measures to objective conditions, subjective evaluations were strongly related to most of the factors.

\subsection{Measures of Multidimensional Deprivation}

In 2010, the UNDP-HPI was supplanted by assessments of 
a multi-dimensional poverty index (UNDP-MPI). The UNDP-MPI, likewise referred to as an index of acute poverty, measures a person's failure to meet simultaneously minimum international in markers identified with the Millennium Development Goals [3]. In this view, it recognizes poverty by utilizing ten indicators spreading over the education, wellbeing and way of life measurements, and decides the quantity of multi-dimensionally poor people.

\section{Research Methodology}

\subsection{Methodology}

This is a socio-economic survey research; the ultimate goal of the research is to find the social problem by using a participatory way. Especially this paper considers the socio-economic condition of the household and measures the condition of poverty by using MPI. The ways of completing the study is to run towards the objectives of the work. Reconnaissance survey to the study area is required mostly for questionnaire preparation and sample design.

As the study mainly based on the primary data, questionnaire preparation is an important part of this study. After performing the observation survey in the study area, a clear and structured questionnaire has been developed. In the process of questionnaire survey, the respondents has been requested to answer the questions, carefully and honestly, regarding their socio-economic conditions and the resource base, their income generating activities and living condition.

In survey sampling method, weights could be connect to the information to change for the sample design, particularly in simple random sampling. Sampling is the way toward choosing units from a population of interest so that by concentrate the example one may reasonably sum up comes about back to the population from which they were picked [12]. For conducting this research sample size would be 117.
Simple random sampling will be used for this research. Sample size calculation process:

$$
\mathrm{n}=\frac{z^{2} p q N}{(N-1) e^{2}+z^{2} p q}
$$

Where, $\mathrm{n}=$ sample size

$\mathrm{N}=$ population size $=59025[\mathrm{BBS} 2011]$

$\mathrm{Z}=$ Standard normal distribution (set at 1.96 corresponding to a confidence level of $95 \%$ )

$\mathrm{p}=$ Probability of success $(0.5)$

$\mathrm{q}=$ Probability of failure $(0.5)$

$\mathrm{e}=$ Precision level $=(0.09)$

So,

$\mathrm{n}=\{(1.96) 2 \times .5 \times .5 \times 59025\} \div\{(59025-1)(.09) 2+(1.96)$ $2 \times .5 \times .5\}=117$

The sample size is 117 household.

\subsection{Weightage Method}

Calculating MPI used five factors that are assigned same weightage and it is $20 \%$. These factors are financials aspects, education, health, living standard and political aspects. In financial aspects considered four sub factors and these are employment, savings, assets and loan and all these are assigned $5 \%$. In education considered two sub-factors, these are years of schooling and school enrollment children and these two are assigned $10 \%$. In Health considered two sub-factors, these are child sickness and child mortality and these two are assigned same weightage and it is $10 \%$. In living standard considered five sub factors and these are cooking fuel, electricity, sanitation, drinking water and housing floor and all these are assigned same weightage and it is $5 \%$. In political aspects considered two sub-factors, these are access to law and order and voting right and these two are assigned same weightage and it is $10 \%$.

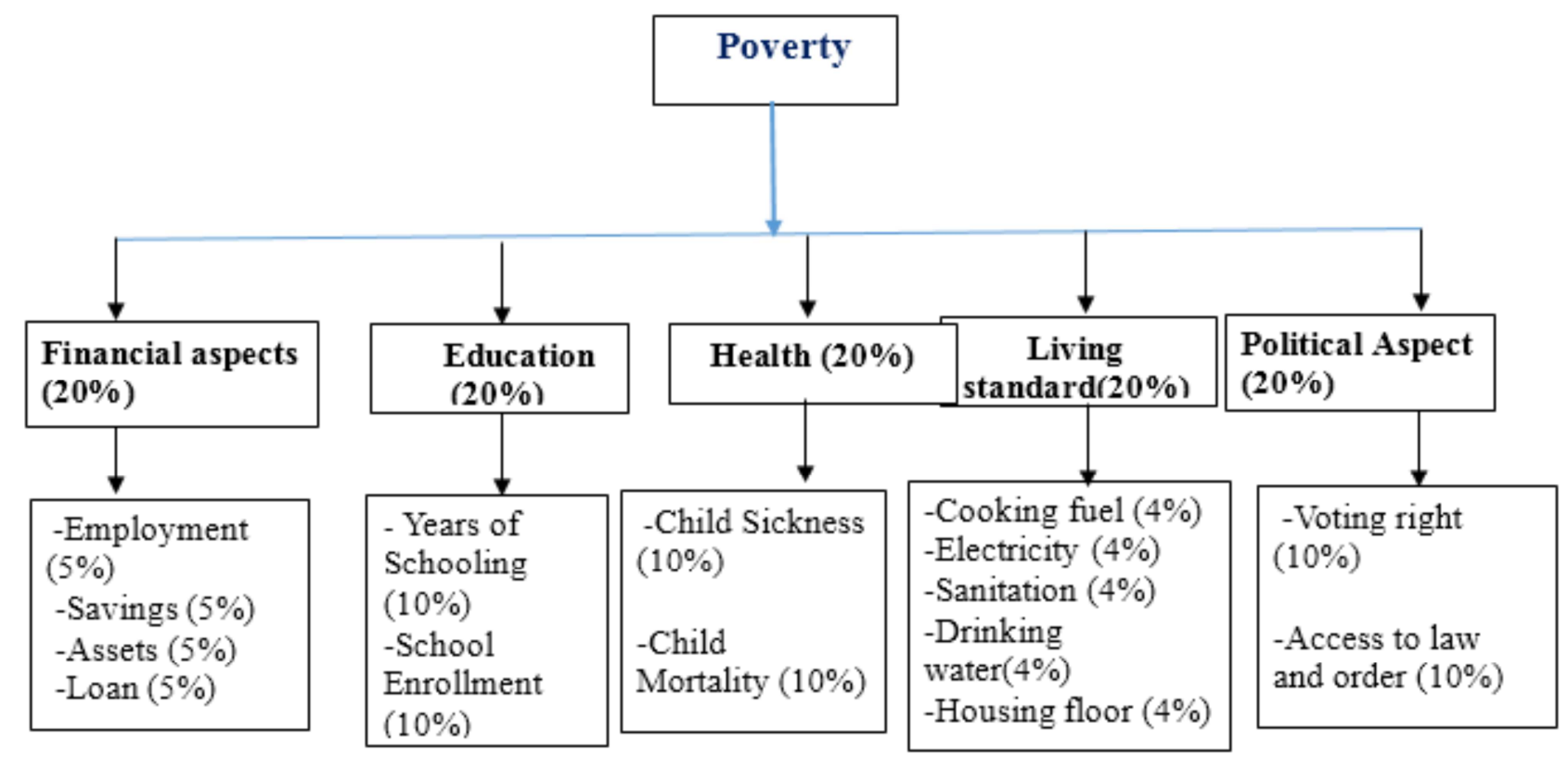

Figure 1. Weightage of Poverty Factors. 


\section{Data Analysis and Findings}

\subsection{Indicator Selection}

From the literature review some indictors are selected under five dimensions. These indicators may be fulfilled the aim of this research which is all about to identify rural poverty in the context of Jalma union. Selected dimensions and indicators are- Financial Aspects (Employment, Savings, Assets and Loan). Education (Five years of schooling. School enrolled).

Health (Child chickens, Child Mortality).

Living Standard (Cooking Fuel, Electricity, Sanitation, Drinking water, Housing floor).

Political Aspects (Voting right, Access to law and order)

\subsection{Multidimensional Poverty Index}

The multidimensional Poverty Index was developed in 2010 by the Oxford Poverty \& Human Development Initiatives and the United Nations Development Program. It is an international measure of acute poverty. And complements traditional income based poverty measures by capturing the severe deprivations that each person faces at the same time with respect to education, health and living standards.

\subsection{Calculation Procedure of MPI}

According to [9],

$$
\mathrm{MPI}=\mathrm{A}^{*} \mathrm{H}
$$

$\mathrm{H}($ head count ratio $)=\mathrm{q} / \mathrm{n} ; \mathrm{q}=$ the number of people who are poor and $n=$ the total population.

$$
\mathrm{A}(\text { Intensity) }=\mathrm{c} / \mathrm{q} \text {; }
$$

$\mathrm{c}=$ deprivation score
Contribution of each dimension $=(\mathrm{cj} / \mathrm{n}) / \mathrm{MPI} ; \mathrm{j}=1,2,3,4$

To identify poor, the deprivation scores for each indicator is summed to obtain the household deprivation score, c. A cutoff of 20 percent, which is equivalent to $1 / 5$ of the weighted indicators, is used to distinguish between the poor and non-poor. If the deprivation score is 20 percent or greater, that household (and everyone in it) is poor. Households with a deprivation score equal to 20 percent are considered to be near multidimensional poverty. Households with a deprivation score of 50 percent or higher are severely poor.

Calculating the contribution of each dimension to multidimensional poverty provides information that can be useful for revealing any area's or a country's configuration of deprivations and can help with policy targeting.

\subsection{Analysis and Data Interpretation}

In Table 1 represents the poverty condition. In here the Chakrakhali village is more poorer than others and its MPI value is also high (0.41) and Basbaria is comparatively richer than others. By using the equation 1 and 2, it found the following result for 10 villages at jalma union.

Table 1. Overall Poverty Condition in Jalma union.

\begin{tabular}{llllll}
\hline Village name & Percent & Poor & HCR & Intensity Poverty & MPI \\
\hline Basbaria & 63.63 & 7 & 0.6 & 0.37 & 0.21 \\
Chak Alipur & 54.54 & 6 & 0.58 & 0.39 & 0.23 \\
Guptamari & 81.81 & 9 & 0.86 & 0.44 & 0.38 \\
Chakrakhali & 90.90 & 10 & 0.9 & 0.45 & 0.41 \\
Dubi & 81.81 & 9 & 0.85 & 0.44 & 0.37 \\
Harintana & 81.81 & 9 & 0.85 & 0.47 & 0.4 \\
Jalma & 72.72 & 8 & 0.73 & 0.47 & 0.34 \\
Krisnonagar & 81.81 & 9 & 0.8 & 0.43 & 0.345 \\
Kolabaria & 81.81 & 9 & 0.84 & 0.42 & 0.35 \\
Kosubunia & 50 & 4 & 0.46 & 0.35 & 0.16 \\
\hline
\end{tabular}

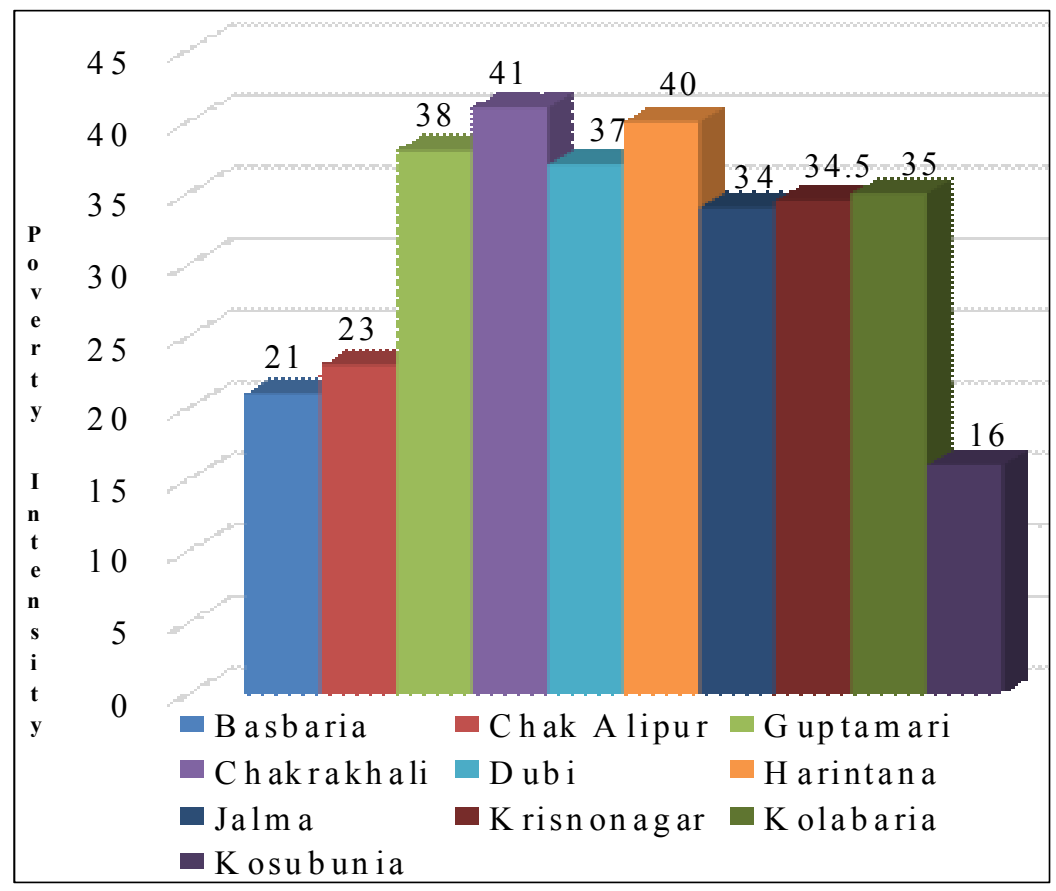

Figure 2. Multidimensional Poverty Condition in Jalma Union. 


\subsection{Poor Household}

Poverty is general scarcity or the state of one who lacks a certain amount of material possessing or money. In poor household, economic development has progressed beyond a certain minimum level because of the poverty problem. In poor household, their economic aspects of poverty focus on material needs, typically including the necessities of daily living, such as food, clothing, shelter or safe drinking water. There are no universal principles by which to determine the minimum threshold of participation equating to full membership of society. Within whole Jalma union the Chakrakhali village was poorer rather than other 9 villages.

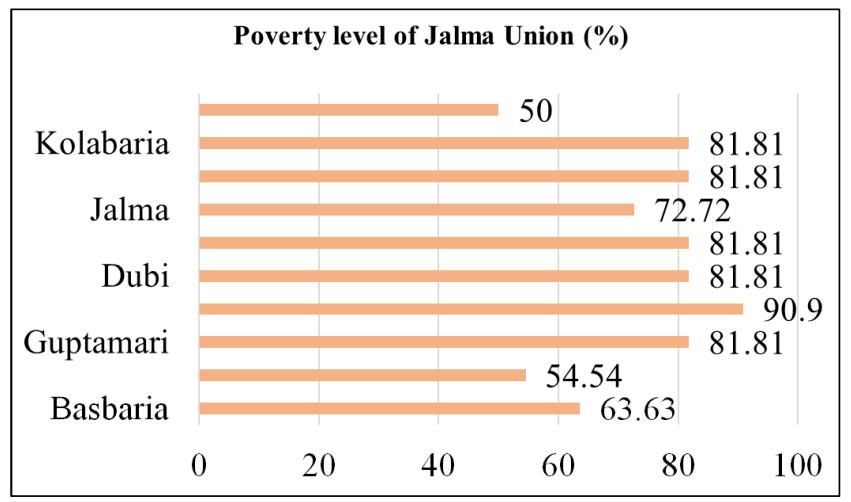

Figure 3. Intensity of Poverty in Jalma Union.

\subsection{Livelihood Asset Pentagon}

Assets refer to the resource base of people. Assets are often represented as a pentagon in the SLF, consisting of the following five categories: natural resources (also called 'natural capital'), physical reproducible goods ('physical capital'), monetary resources ('financial capital'), manpower with different skills ('human capital'), social networks of various kinds ('social capital').

These various categories cover the following types of issues and details:

1. Human capital: labor power, health and nutritional status, skills and education.

2. Natural capital: access to land, water, soil, environment.

3. Social capital: refers to those stocks of social trust, norms and networks that people can draw upon to solve common problems. It is mediated through kin networks and group membership;

4. Physical capital: houses, water supply, vehicles, equipment, livestock.

5. Financial capital: wages, savings, access to credit, net, insurance.

\subsection{Overall Condition of Asset Pentagon for Different Villages}

Showing this chart found that in Asset pentagon physical capital (water supply, housing, vehicle equipment, and livestock) is good of all villages. The overall condition of social capital and natural capital is secondly prominent of all villages. As the study area is rural area the condition of human capital is not so strong. In asset pentagon, financial capital is so much poor of all villages because most of the household living under poverty line.

From this table, it has been seen that in Basbaria village human capital is $23 \%$ on the other hand Krishnonagor village human capital is $38 \%$. In Guptamari village natural capital is $37 \%$ whereas the physical capital reaches to $40 \%$. It should be noted that in Dubi village there is a great different found between natural and financial capital. There is a great similarity natural and physical capital in Harintana village.

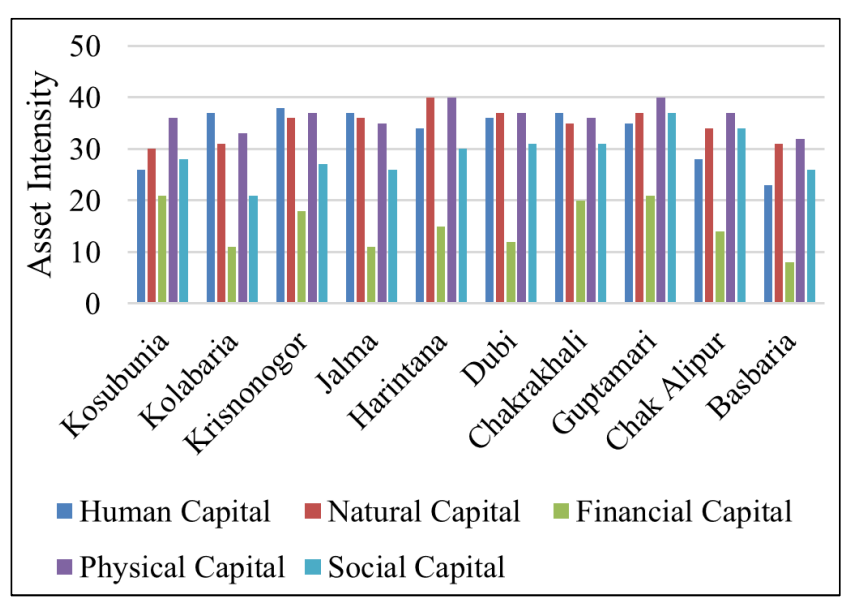

Figure 4. Overall condition of Asset pentagon for various villages.

\subsection{Comparison of Asset Pentagon}

This chart illustrates that the condition of asset pentagon are varies in different village. The percentage of the condition of asset pentagon indicates the household condition as well as household economic condition. In poor household, they can't use different types of asset because they can't bear sufficient money for buying different types of asset.

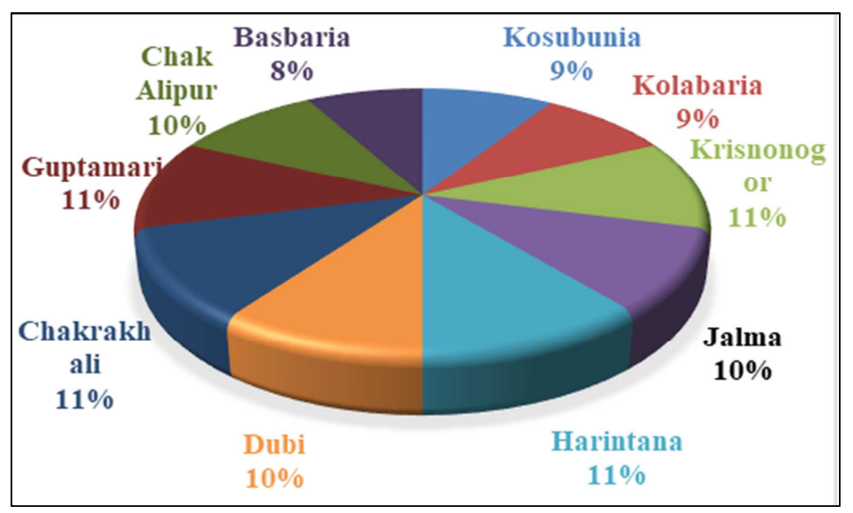

Figure 5. Comparison of Asset Pentagon.

Showing this chart found that asset pentagon in Haintana, Chakrakhali, Guptamari and Krisnonogor village is $11 \%$ and it is higher than others village. In Jalma, Dubi and Chak Alipur village the condition of asset pentagon is moderate and it is $10 \%$. In Kolabaria and Kosubunia village the condition of asset pentagon is $9 \%$ and Basbaria village the condition of 
asset pentagon is lower than others and it is only $8 \%$.

\subsection{Overall Situation of Asset Pentagon in Jalma Union}

This chart illustrates the condition of asset pentagon (human capital, natural capital, financial capital, physical capital and social capital) in Jalma union. In human capital people's health and ability to work, and the knowledge and skills they have acquired over generations of experience and observation, constitute their human capital. For individuals in rural regions, natural capital, including resources, for example, arrive, water, woods assets and domesticated animals are clearly of key significance for the generation of sustenance and wage. The financial capital available to rural households may come from the conversation of their product into cash in order to cover periods when production is less or to invest in other activities. Physical capital may include tools and equipment as well as infrastructure such as roads, ports, landing places etc. Access to these as well as other forms of infrastructure such as water supply or health care facilities will influence people's ability to earn an adequate livelihood. In social capital, the way in which people work together, both within the household and in the widen community, is of key importance for household livelihoods and it also increase interaction within the household.

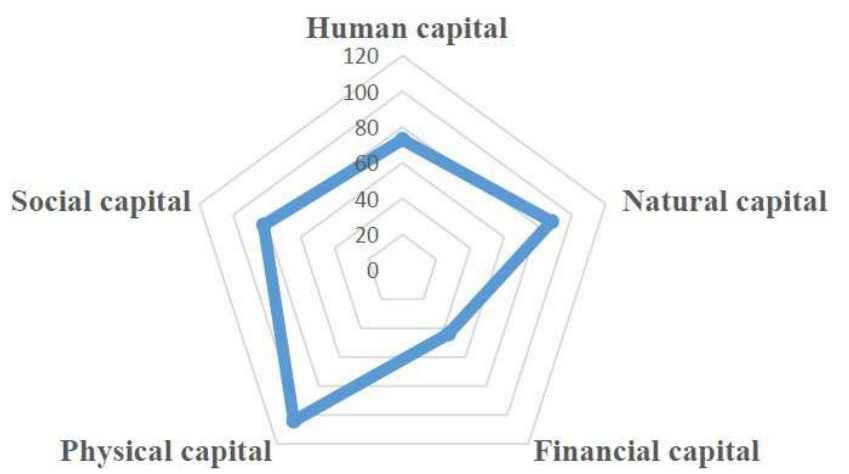

Figure 6. Overall situation of Asset pentagon in Jalma union.

Showing this chart found that in Asset pentagon physical capital (water supply, housing, vehicle equipment, livestock) is better than others. The overall condition of social capital and natural capital is secondly prominent than others. As the study area is rural area the condition of human capital is not so strong. In asset pentagon, financial capital is so much poor because most of the household living under poverty line.

\subsection{Findings}

From the study, there are found some findings that are associated with socio-economic condition as well as condition of living standard. The major findings are-

a). About $68 \%$ households are not well to do. Because of physical and economic condition is very miserable. In Jalma union access to economic opportunities outside agriculture would help increasing consumption, but low educational attainment, poor access to financial markets, and weak infrastructure prevent many smallholders from participating in nonfarm activities.

b). Multi-dimensional poverty (financial aspects, education, health, living standard and political aspects) is more than income poverty.

c). The value of MPI is about $40 \%$ which is found in Chakrakhali and Harintana village. In Dubai and Guptamari village the value of MPI is almost equal, it is about 35\%. In Jalma, Krisnonogor and Kolabaria village the value of MPI is almost equal, it is above $30 \%$. In Kosubunia village the value of MPI is low and it is about $15 \%$.

d). About $12 \%$ of household of Chakrakhali village is poor and it is the prominent level. Otherwise $11 \%$ of household in Guptamari, Kolabaria and Krishnonagar villages are poor. 10\% household of Jalma village is poor and $9 \%$ in Basbaria. In Kosubunia and Chak Alipur only $7 \%$ of households are poor.

e). From the study area found that $34 \%$ people (specially children) are malnourished due to poverty. Their parents cannot afford healthy food for them.

f). In the study area $84 \%$ house type is Katcha and $12 \%$ house type is semi-pucca. Only $4 \%$ house type is pucca. So, their housing condition is very bad.

g). From the study $85 \%$ sanitation condition is semi-pucca and it is higher than others and $8 \%$ of sanitation condition is katcha. Only $7 \%$ of sanitation condition is pucca.

h). Very few percentage of household flooring type is pucca and it is totally $15 \%$, maximum household flooring type is made by mud, and it is $85 \%$. So, the household flooring type of this union is very bad.

i). Among 66\% households have own connection and 4\% households have no connection of electricity. Some households are deprived of own connection of electricity supply and it is about $30 \%$.

j). About 14\% children who were suffering from malnourishment and other diseases and died at their early age.

k). In our country, rural people have no access to law and order because they amnestied poverty. In Jalma union $87 \%$ people have no access to law and order.

1). About $6.8 \%$ respondents are completely illiterate. A large proportion of the respondents are educated up to class five that is $31.6 \%$.

\section{Conclusions}

Poverty is the curse of human life. It deteriorates the quality of human life. It affects human happiness, peace and all their expected wish. And this thesis can explore the real scenario of poverty conditions of different villages of Batiaghata union in Bangladesh. We have to found that the poverty level of Jalma union in Khulna city is not good. The intensity level of most of the area that we have to survey especially the village area is not well off. Physical and economic condition is very miserable in Jalma union. There is no access to economic opportunities, poor access to financial markets, and weak infrastructure prevents many smallholders from participating in nonfarm activities. Especially the poor leaded very miserable life. There should provide many nonfarm activities for improving their living condition. So, it is essential, 
government to take necessary steps for removing poverty of this area and the NGOs and government collaboration is so much essential for this. Government should also provide job opportunity for unemployed person within the poor areas.

\section{References}

[1] Alkire, S., \& Foster, J. (2011). Counting and multidimensional poverty measurement. Journal of public economics, 95 (7), 476-487.

[2] Alkire, S, Santos, \& M. E. (2010). Acute Multidimensional Poverty: A New Index for Developing Countries.

[3] Alkire, S., \& Santos, M. E. (2014). Measuring acute poverty in the developing world: Robustness and scope of the multidimensional poverty index. World Development, 59, 251-274.

[4] Beverly, S. G. (2001). Measures of material hardship: Rationale and recommendations. Journal of Poverty, 5 (1), 23-41.

[5] Carle, A., Baumann, K., and Short, K. (2009). Assessing the measurement and structure of material hardship in the United States. Social Indicators Research, Vol. 92, pp. pp. 35-51.

[6] Honeycutt, T. C., Marshall, L. L., \& Weston, R. (2001). Toward ethnically specific models of employment, public assistance, and victimization. Violence Against Women, 7 (2), 126-140.

[7] Mitra, S., \& Brucker, D. (2014). Poverty and Disadvantage through a multidimensional lens in the United States (No. 5). Fordham University discussion paper.

[8] Orshansky, M. (1965). Counting the poor: Another look at the poverty profile. Soc. Sec. Bull., 28, 3 .

[9] Jahan, S. (2016). Human development report 2016: human development for everyone. United Nations Development Programme (UNDP), New York, NY. [Google Scholar].

[10] Osmani, S. R., \& Latif, M. A. (2013). The Pattern and Determinants of Poverty in Rural Bangladesh, 2000-2010. Institute of Microfinance.

[11] Ravallion, M. (2012). Troubling tradeoffs in the human development index. Journal of Development Economics, 99 (2), 201-209.

[12] Trochim, W. M. (2006). Qualitative measures. Research Measures Knowledge Base, 361.

[13] Wagle, U. R. (2009). Capability deprivation and income poverty in the United States, 1994 and 2004: Measurement outcomes and demographic profiles. Social Indicators Research, 94 (3), 509.

[14] World Bank (2000). World Development Report 2000-2001. 